\title{
Harnessing SmartPhones to Personalize Nutrition in a Time of Global Pandemic
}

\author{
Niv Zmora ${ }^{1,2,3}$ and Eran Elinav $1,4, *$ (D) \\ 1 Immunology Department, Weizmann Institute of Science, Rehovot 7610001, Israel; niv.zmora@weizmann.ac.il \\ 2 The Sackler Faculty of Medicine, Tel-Aviv University, Tel Aviv 6997801, Israel \\ 3 The Research Center for Digestive Tract and Liver Diseases, Tel Aviv Sourasky Medical Center, \\ Tel Aviv 6423906, Israel \\ 4 Division of Cancer-Microbiome Research, DKFZ, 69120 Heidelberg, Germany \\ * Correspondence: eran.elinav@weizmann.ac.il or e.elinav@dkfz-heidelberg.de
}

check for

updates

Citation: Zmora, N.; Elinav, E. Harnessing SmartPhones to Personalize Nutrition in a Time of Global Pandemic. Nutrients 2021, 13, 422. https://doi.org/10.3390/ nu13020422

Academic Editor: Carlo Agostoni Received: 8 November 2020

Accepted: 26 January 2021

Published: 28 January 2021

Publisher's Note: MDPI stays neutral with regard to jurisdictional claims in published maps and institutional affiliations.

Copyright: (c) 2021 by the authors. Licensee MDPI, Basel, Switzerland. This article is an open access article distributed under the terms and conditions of the Creative Commons Attribution (CC BY) license (https:// creativecommons.org/licenses/by/ $4.0 /)$.

\begin{abstract}
The soar in COVID-19 cases around the globe has forced many to adapt to social distancing and self-isolation. In order to reduce contact with healthcare facilities and other patients, the CDC has advocated the use of telemedicine, i.e., electronic information and telecommunication technology. While these changes may disrupt normal behaviors and routines and induce anxiety, resulting in decreased vigilance to healthy diet and physical activity and reluctance to seek medical attention, they may just as well be circumvented using modern technology. Indeed, as the beginning of the pandemic a plethora of alternatives to conventional physical interactions were introduced. In this Perspective, we portray the role of SmartPhone applications (apps) in monitoring healthy nutrition, from their basic functionality as food diaries required for simple decision-making and nutritional interventions, through more advanced purposes, such as multi-dimensional data-mining and development of machine learning algorithms. Finally, we will delineate the emerging field of personalized nutrition and introduce pioneering technologies and concepts yet to be incorporated in SmartPhone-based dietary surveillance.
\end{abstract}

Keywords: Nutrition app; smartphone; nutrition; COVID-19

\section{The Pandemic Information Age}

SmartPhone ownership is estimated at $45 \%$ of the world's population for 2020 , and this figure is only expected to increase over the next years, especially in developing nations. As mobile devices are prevalent, carried around by users throughout their daily lives and offer various sensing modalities, they are compelling targets of data collection, monitoring and interaction, allowing not only for facilitating user feedback, but also for offering accessible custom-made interventions.

The COVID-19 pandemic is unique in the sense that it employed SmartPhone-based technologies for epidemiological purposes. Population surveillance and screening for the disease were carried out in the United States through an app that collected SmartWatch and activity tracker data, as well as surveys for self-reported symptoms [1,2]. As such, a study conducted on large cohorts from the United States and the United Kingdom, based on self-reporting of symptoms through a SmartPhone app, revealed that loss of sense of smell and taste could be included as part of routine screening for COVID-19 [3,4]. In China, mobile phone geolocation data ware used to map the distribution of confirmed cases to assist in decision-making to slow the rate of transmission [5]. Similarly, contacts of infected users were tracked using GPS data or Bluetooth (short-range radio) signals [6,7].

Additionally, SmartPhone-based technology and auxiliary plug-in devices can assist in case identification. Viral RNA can be detected through point-of-care testing using a portable assay and a SmartPhone-based reader [8]. Voice analysis is an emerging field 
that strives to detect specific vocal 'biomarkers', such as shortness of breath and cough, associated with COVID-19 from recordings obtained by mobile devices [9].

More digital technologies developed to diagnose or curb COVID-19 spread are extensively covered elsewhere [10].

\section{The Advent of SmartPhone Apps in Dietary Surveillance}

Nutrition apps provide a simple way for the user to log meals and other daily activities, obtain nutritional information on food items and receive automatic push notifications based on preset thresholds and conditions. They allow dietitians and other medical personnel to assess the users' compliance and diet transgressions, track their behaviors, set goals, send motivational messages, and analyze the data. These features rendered these apps an attractive means of providing remote dietary care to users, irrespective of their COVID-19 status. Herein, we will highlight the various usages of nutrition apps, and then focus on special considerations pertaining to the COVID-19 pandemic.

The last decade has witnessed a surge in nutrition apps, rendering SmartPhones a validated dietary assessment tool [11,12]. Several studies have suggested that users were more compliant with dietary tracking using Smartphone apps compared to the traditional paper-and-pencil food diaries [13], although these findings were inconsistent [14]. Furthermore, a recent international survey completed by healthcare professionals (including dietitians, doctors and nurses) revealed that $45.5 \%$ recommended nutrition apps to their patients [15].

Nutrition apps have been widely used to promote dietary interventions, such as increasing fruit and vegetable consumption or decreasing saturated fat and sugar-sweetened beverage intake [16-19]. They have also served as a tool in the armamentarium to prevent or combat obesity in children [20], adolescents [21], and adults with specific medical conditions, such as pregnancy [22] and type 2 diabetes mellitus (T2DM) [23]. With regards to the latter, a simple intervention of sending text messages providing information, motivation, support and reminders related to diabetes management improved glycemic control in poorly controlled individuals with T2DM [24]. Nutrition apps have been used in research for other indications, including maintaining a low-salt diet in patients suffering from cardiovascular disease [25], optimizing food choices for patients suffering from nephrolithiasis [26], and monitoring energy intake and nutritional behaviors in elite athletes [27,28]. It should be noted, however, that many of the studies that showed promising results for SmartPhone-based strategies were limited by short-term intervention periods and were not sufficiently methodologically rigorous.

The call for social distancing and self-isolation during the COVID-19 pandemic has promoted a surge in SmartPhone apps as alternatives to social interactions. Various services, including retail businesses and healthcare have adapted to the changing reality with telecommunication. Likewise, diet and nutrition advice is facing a burning need to shift from physical clinical encounters to remote interactions. Patients with COVID-19, especially the elderly, people of low socioeconomic and educational status or those with underlying medical conditions require continuous dietary care, presenting more complex and challenging problems for healthcare professionals, including increased catabolism, nutritional deficiencies or altered physiology [29-32]. Even individuals without COVID19, who suffer from chronic diseases or malnutrition, may require adaptations to reduce food insecurity during the pandemic [33]. Furthermore, healthy individuals who have experienced lifestyle changes and become sedentary due to imposed lockdowns may need dietary modifications, and others may benefit from remote nutritional counseling to counteract psychological distress due to the health emergency situation [34,35]. In the following sections we will illustrate the role of nutrition SmartPhone apps as means to tackle these issues. 


\section{Requirements of Nutrition Apps}

Generating an effective nutrition SmartPhone app is a task that requires numerous considerations and encompasses a multi-disciplinary effort and a collaboration of product managers, software engineers, medical personnel, scientists and data analysts. Apps should comply with a standardized Nutrition Care Process (NCP), and therefore follow the framework of nutrition assessment, diagnosis, intervention, monitoring and evaluation to ensure efficient and reliable remote continuous care [36]. All apps should offer an expeditious and simplified means to log or report meal intake, and many implement additional features of planning, reminding, coaching, boosting motivation and providing information (Figure 1).
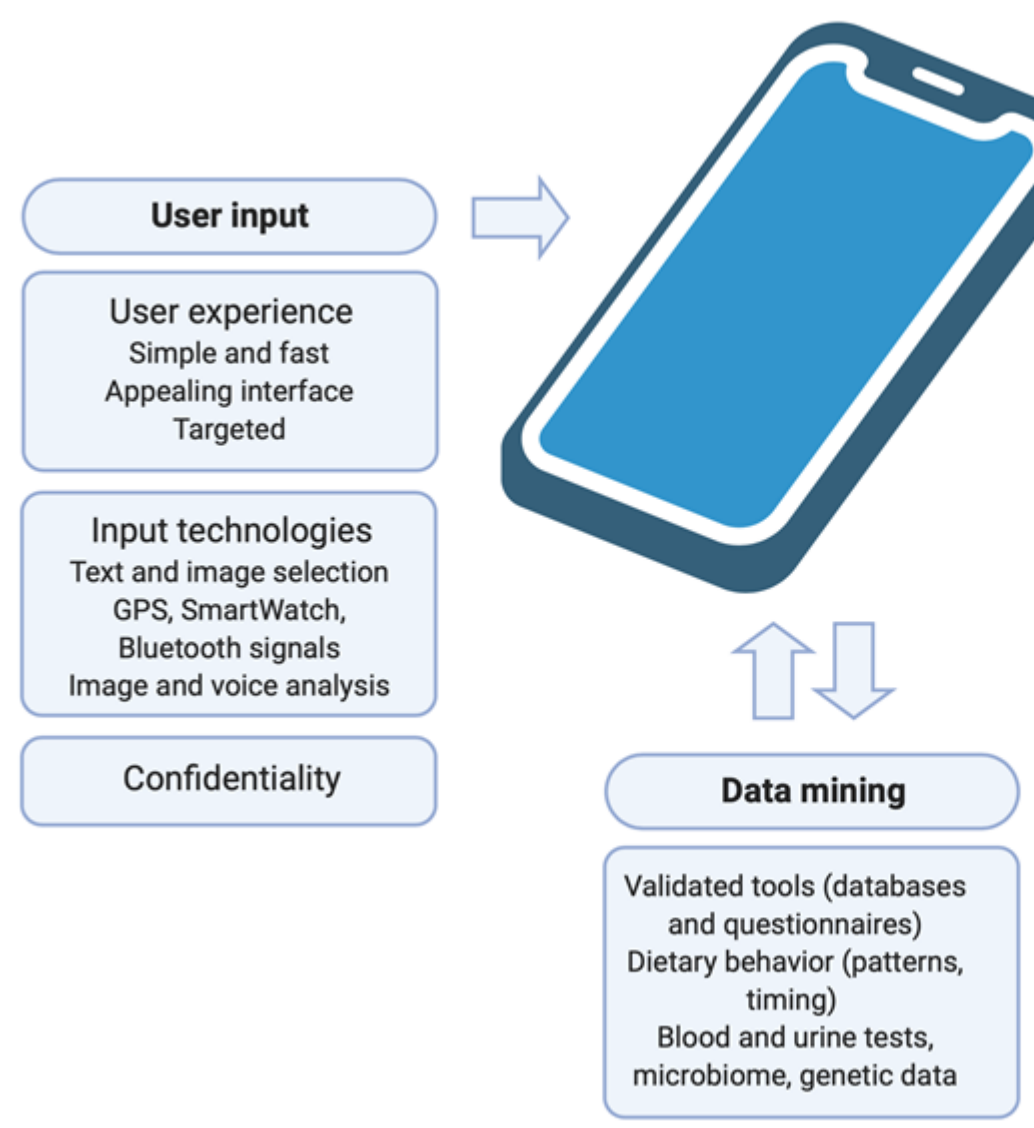

Figure 1. Requirements of nutrition apps. SmartPhone apps consist of several modules: the interface should provide compelling user experience and utilize advanced technologies to facilitate comprehensive data collection, and users' confidentiality should be maintained. Data mining should be based both on entries recorded by the app and externally derived data and should be suitable for population-based studies. Data analysis should be performed using artificial intelligence and subsequent recommendations should be produced at a personal level (Created with BioRender.com).

User experience is of paramount importance. As users adherence tends to abate over time [37] and is directly correlated with the app's efficacy [38], great emphasis should be placed on its target audience, for instance, while a vivid interface may appeal to children, elderly users may require enhanced accessibility. The design should be attractive, enjoyable and easy-to-use, and navigation should be swift and seamless. The most prevalent recording methods used on mobile phone platforms are electronic food diaries (assisted by textual or picture-based databases), 24-h recall, barcode scanners and food photograph analysis. Employing image analysis technologies in nutrition apps as an alternative to written records has considerably evolved over the last years. Initially, carbohydrate estimation required lengthy redrawing of food items [39]. Subsequently, artificial intelligence allowed for calorie, carbohydrate or macronutrient estimation of meal images, which 
outperformed or was non-inferior to evaluation by experienced dietitians [40,41]. Image analysis technologies can be stand-alone or complimented by a voice recording to explain the contents of the photograph and then analyzed by a dietitian [42]. Novel technologies offer food image recognition with increasing accuracy harnessing deep neural network architectures [43].

Food databases should not only be comprehensive and up-to-date, but also customized to fit the users' locale. As such, tables of food composition should be country-specific to allow for reliable and accurate reporting of meals. Additionally, neonates, inpatients or individuals suffering from chronic medical conditions should be able to log nutritional formulas and food supplements. Decision-making should rely on validated methods, for instance a recent study proposed a remote nutritional screening tool during the COVID-19 pandemic based on the Malnutrition Universal Screening Tool (MUST) and the SARC-F questionnaire [44]. Finally, user confidentiality and data protection principles must be ensured in every nutrition app, as stipulated by the General Data Protection Regulation (GDPR). Namely, data reported by users should be collected and stored in an anonymized (or pseudonymized) manner, allowing full traceability while ensuring participant protection. Meticulous security audit, including penetration tests and vulnerability assessments should be conducted by the app developers to prevent data leaks. Data must not be shared or transmitted to third-party companies without informed consent, which should disclose all data sharing practices. Additionally, the Children's Online Privacy Protection Act (COPPA) should be enforced in nutrition apps addressed to minors.

\section{Scientific Applications of Nutrition Apps and Their Pitfalls}

Data collected by nutrition apps are usually processed by individuals and their healthcare providers to track their compliance with a dietary regimen and assess the effect of nutrition interventions. Nonetheless, this information, when acquired adequately on large populations, can serve as real-world data, a complementary source to randomized control trials to reveal statistically significant health trends and yield robust and meaningful conclusions in nutritional management. These studies are particularly crucial in times of changing social and economical behaviors, such as the COVID-19 pandemic. Furthermore, nutritional data interlaced with blood tests results deemed potentially valuable and warrants further research in patients with COVID-19, as circumstantial evidence linked between deficiencies in some dietary constituents and disease severity $[45,46]$.

As previously implied, albeit effective in increasing "attentive eating" as well as promoting specific dietary modifications among users affected by medical conditions (e.g., reducing salt intake [47]), nutrition apps are often not more valid or reliable than conventional methods [48], and do not always translate into clinical benefit (e.g., cardiovascular risk reduction [49], weight loss [50] or prevention of gestational diabetes mellitus [51]), posing marginal added value compared to standard counseling on diet and physical activity [49]. These discouraging findings merit reevaluation of universal dietary recommendations and call for a more individualized approach when designing nutrition interventions.

\section{Practicing Personalized Diet with Nutrition Apps}

A large body of evidence has demonstrated that there is great variability in responses to similar food among different individuals [52]. This variability derives from a multitude of factors, including personal parameters as well as the consumer's environmental milieu. Therefore, optimal dietary planning should be made in the context of an individual and their unique features, rendering the notion of "one-diet-fits-all" obsolete (Figure 2). Host-intrinsic variability stems from genetic and epigenetic factors. As such, methylation of adipogenic genes correlated with insulin resistance after a specific nutritional intervention [53]. 


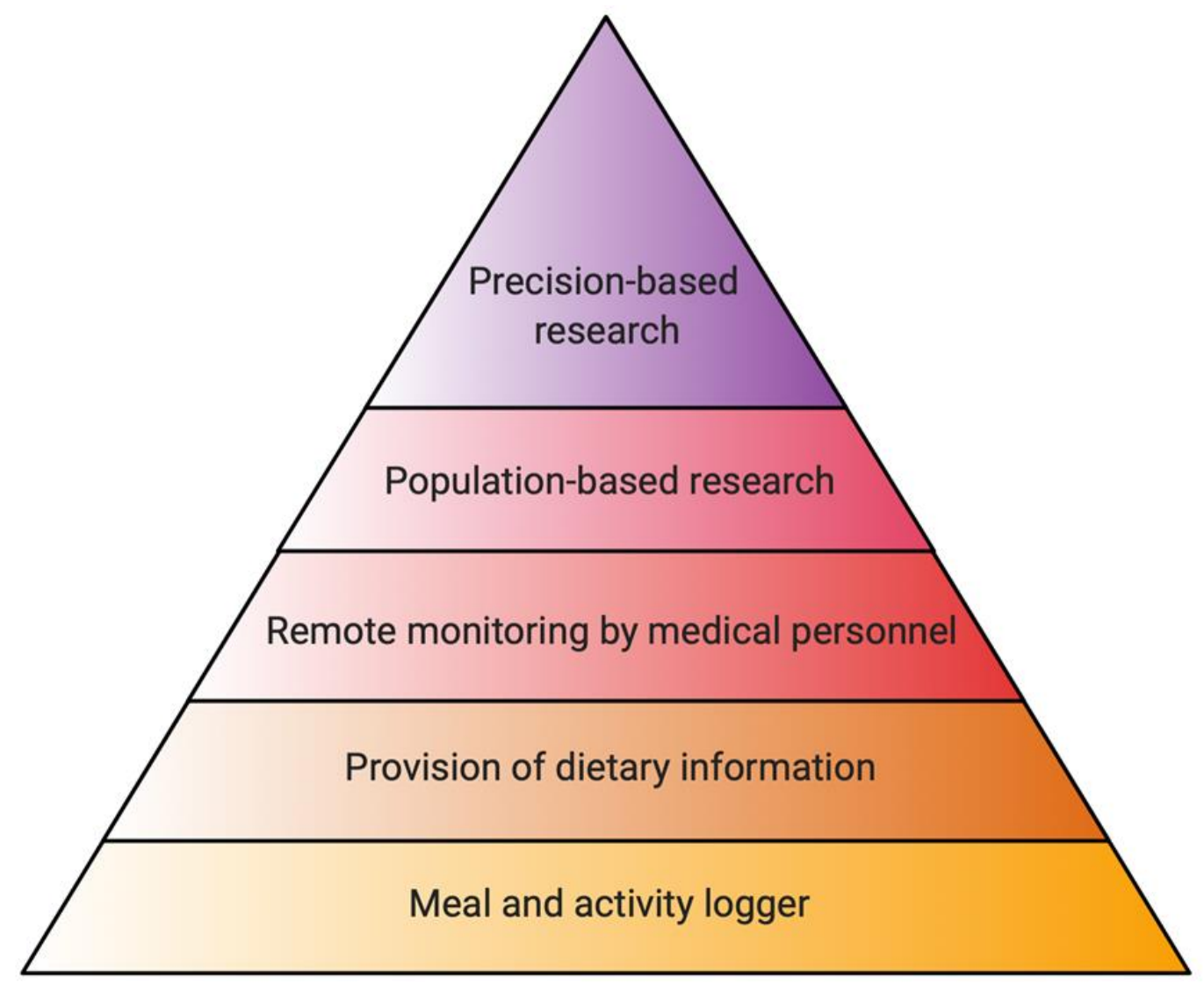

Figure 2. -Strata of nutrition apps functionality. The foundation of every nutrition SmartPhone app rests on a user interface to log meals and daily activities. Most apps provide visualization of the recorded data and information to the user. More advanced features include direct supervision and remote monitoring by medical personnel. High-level operations on collected data are populationand precision-based studies (Created with BioRender.com).

Environmental factors that affect responses to dietary interventions include eating patterns, timing of meals and their relation to physical activities and to psychological stress [54]. These factors, termed dietary behavior, can be modeled based on SmartPhone data and dictate interventions [55], as advanced sensing capabilities embedded in mobile devices allow for estimation of daily energy expenditure from phone accelometry and elucidating time-location eating patterns using GPS data [55]. Machine learning techniques employed on these data may assist in tracing and predicting dietary lapses during dietary interventions, and have been shown to result in greater precision when applied on individually segregated data, rather than data pooled from a group of individuals [55,56].

Of the many factors shaping individualized responses to food the gastrointestinal microbiome has been gaining increasing attention. The microbiome, constituting trillions of bacteria and other microorganisms, has a major role in food digestion and exerts a profound metabolic effect on the host. Studies have found that certain microbiome features might account for altered responses to a particular dietary intervention, for instance a high ratio between two bacterial genera, Prevotella and Bacteroides, in stool was associated with greater weight loss [57] and improved glucose metabolism [58].

Our lab has profiled a large cohort of individuals in terms of anthropometrics, blood tests and stool microbiome composition and function, and tracked their blood glucose levels with continuous glucose monitors for a period of one week, while they were instructed to keep a food and activity diary through a designated SmartPhone app. We found, like others, a high inter-individual variability in post-meal glucose responses to the same food. We then associated these differences with individual features and constructed a decision treebased machine-learning algorithm to predict post-meal glucose responses. Eventually, we 
conducted a small-scale interventional study to prove that individualized menus devised based on our algorithm could effectively maintain normoglycemia [59]. Similarly, a recent study proposed using a SmartPhone application to manage gestational diabetes mellitus in the time of COVID-19. The app incorporated diet transgressions, blood glucose values and ketonuria to make adjustment recommendations regarding diet and insulin treatment [60]. In summary, personalized nutrition is a holistic multi-faceted concept, which relies on various host, microbiome and environmental variables. The widespread use of nutrition SmartPhone apps complemented by biomarkers and advanced multi-omics analyses set the groundwork for exploring, practicing and fine-tuning personalization of diet.

\section{Future Prospects}

We envision that the commodification and rapid developments in mobile technology and the recent breakthroughs in big data analysis will result in an upcoming burgeon to the field of personalized nutrition. Incorporating multi-dimensional host and microbiome data profiling with tracking of food intake and food behavior will yield high-quality tailormade dietary recommendations, which can be optimized for specific objectives or medical conditions.

Studies will further explore determinants of intra-individual differences, such as the addition or omission of micronutrients [61], the effect of prior meals on the response to consequent meals [62] or the effect of the circadian phase on responses to food [63]. With regards to the latter, it has been shown that restriction of daily eating hours was associated with reduced body weight and long-lasting improvement in various symptoms [64].

Ongoing alterations in individual features will require dietary recommendations to be periodically adjusted. This and the aforementioned associations between several micronutrients levels and COVID-19 severity may require frequent blood tests or microbiome profiling, or the development of plug-in assays for point of care quantification of nutrient deficiencies, such as serum iron, vitamin A and vitamin B12 [65,66].

Moreover, SmartPhone apps will transcend beyond provision of nutritional recommendations to provide active behavior modifications, so users will implicitly make healthier choices. An interesting example to this notion was witnessed in users of the mobile app Pokémon GO, who increased their number of steps after installation of the game [67].

Thinking outside the box may aid in improving compliance and instilling motivation to pursue nutritional and lifestyle interventions. For instance, one study proposed an integrative system for adolescents, which consists of garments embedded with monitoring devices, activity trackers, a web portal and a several smartphone apps with reward and a gamification modules [68]. Likewise, interface between nutrition apps and social networking websites may boost adherence in some users.

With these ideas in mind, dietary surveillance and decision-making in this time of global pandemic may pose many challenges; however SmartPhone apps may potentially overcome them and pave the way towards augmented and more effective personalized nutrition.

Funding: This research received no external funding.

Institutional Review Board Statement: Not applicable.

Informed Consent Statement: Not applicable.

Data Availability Statement: Not applicable.

Acknowledgments: We thank the members of the Elinav lab, and the members of the DKFZ cancermicrobiome division for discussions. E.E. is the supported by Yael and Rami Ungar; the Leona M. and Harry B. Helmsley Charitable Trust; Adelis Foundation; Pearl Welinsky Merlo Scientific Progress Research Fund; Lawrence and Sandra Post Family Foundation; Daniel Morris Trust; Park Avenue Charitable Fund; The Hanna and Ludwik Wallach Cancer Research Fund; Howard and Nancy Marks Charitable Fund; Aliza Moussaieff; Estate of Malka Moskowitz; Estate of Myron H. Ackerman; Estate of Bernard Bishin for the WIS-Clalit Program; Donald and Susan Schwarz; The 


\begin{abstract}
V. R. Schwartz Research Fellow Chair; and by grants funded by the European Research Council; Israel Science Foundation; Israel Ministry of Science and Technology; Israel Ministry of Health; the Helmholtz Foundation; Else Kroener Fresenius Foundation; Garvan Institute; European Crohn's and Colitis Organization; Deutsch-Israelische Projektkooperation; and Welcome Trust. E.E. is the incumbent of the Marc and Tania Feldmann Professorial Chair; a senior fellow, Canadian Institute of Advanced Research (CIFAR); and an international scholar, The Bill \& Melinda Gates Foundation and Howard Hughes Medical Institute (HHMI).
\end{abstract}

Conflicts of Interest: E.E. is a paid consultant at DayTwo and BiomX.

\title{
References
}

1. Quer, G.; Radin, J.M.; Gadaleta, M.; Baca-Motes, K.; Ariniello, L.; Ramos, E.; Kheterpal, V.; Topol, E.J.; Steinhubl, S.R. Wearable sensor data and self-reported symptoms for COVID-19 detection. Nat. Med. 2020, 27, 73-77. [CrossRef] [PubMed]

2. Segal, E.; Zhang, F.; Lin, X.; King, G.; Shalem, O.; Shilo, S.; Allen, W.E.; Alquaddoomi, F.; Altae-Tran, H.; Anders, S.; et al. Building an international consortium for tracking coronavirus health status. Nat. Med. 2020, 26, 1161-1165. [CrossRef]

3. Menni, C.; Valdes, A.M.; Freidin, M.B.; Sudre, C.H.; Nguyen, L.H.; Drew, D.A.; Ganesh, S.; Varsavsky, T.; Cardoso, M.J.; El-Sayed Moustafa, J.S.; et al. Real-time tracking of self-reported symptoms to predict potential COVID-19. Nat. Med. 2020, 26, 1037-1040. [CrossRef]

4. Drew, D.A.; Nguyen, L.H.; Steves, C.J.; Menni, C.; Freydin, M.; Varsavsky, T.; Sudre, C.H.; Jorge Cardoso, M.; Ourselin, S.; Wolf, J.; et al. Rapid implementation of mobile technology for real-time epidemiology of COVID-19. Science 2020, 368, 1362-1367. [CrossRef]

5. Jia, J.S.; Lu, X.; Yuan, Y.; Xu, G.; Jia, J.; Christakis, N.A. Population flow drives spatio-temporal distribution of COVID-19 in China. Nature 2020, 582, 389-394. [CrossRef]

6. Servick, K. Can phone apps slow the spread of the coronavirus? Science 2020, 368, 1296-1297. [CrossRef]

7. Ferretti, L.; Wymant, C.; Kendall, M.; Zhao, L.; Nurtay, A.; Abeler-Dörner, L.; Parker, M.; Bonsall, D.; Fraser, C. Quantifying SARS-CoV-2 transmission suggests epidemic control with digital contact tracing. Science 2020, 368, eabb6936. [CrossRef]

8. Ganguli, A.; Mostafa, A.; Berger, J.; Aydin, M.Y.; Sun, F.; Stewart de Ramirez, S.A.; Valera, E.; Cunningham, B.T.; King, W.P.; Bashir, R. Rapid isothermal amplification and portable detection system for SARS-CoV-2. Proc. Natl. Acad. Sci. USA 2020, 117, 22727-22735. [CrossRef] [PubMed]

9. Anthes, E. Alexa, do I have COVID-19? Nature 2020, 586, 22-25. [CrossRef] [PubMed]

10. Budd, J.; Miller, B.S.; Manning, E.M.; Lampos, V.; Zhuang, M.; Edelstein, M.; Rees, G.; Emery, V.C.; Stevens, M.M.; Keegan, N.; et al. Digital technologies in the public-health response to COVID-19. Nat. Med. 2020, 26, 1183-1192. [CrossRef] [PubMed]

11. Carter, M.C.; Burley, V.J.; Nykjaer, C.; Cade, J.E. My Meal Mate (MMM): Validation of the diet measures captured on a smartphone application to facilitate weight loss. Br. J. Nutr. 2013, 109, 539-546. [CrossRef] [PubMed]

12. Chmurzynska, A.; Mlodzik-Czyzewska, M.A.; Malinowska, A.M.; Czarnocinska, J.; Wiebe, D. Use of a smartphone application can improve assessment of high-fat food consumption in overweight individuals. Nutrients 2018, 10, 1692. [CrossRef] [PubMed]

13. Wharton, C.M.; Johnston, C.S.; Cunningham, B.K.; Sterner, D. Dietary self-monitoring, but not dietary quality, improves with use of smartphone app technology in an 8-week weight loss trial. J. Nutr. Educ. Behav. 2014, 46, 440-444. [CrossRef] [PubMed]

14. Spring, B.; Pellegrini, C.A.; Pfammatter, A.; Duncan, J.M.; Pictor, A.; McFadden, H.G.; Siddique, J.; Hedeker, D. Effects of an abbreviated obesity intervention supported by mobile technology: The ENGAGED randomized clinical trial. Obesity 2017, 25, 1191-1198. [CrossRef]

15. Vasiloglou, M.F.; Christodoulidis, S.; Reber, E.; Stathopoulou, T.; Lu, Y.; Stanga, Z.; Mougiakakou, S. What healthcare professionals think of "nutrition \& diet" apps: An international survey. Nutrients 2020, 12, 2214. [CrossRef]

16. Bakırci-Taylor, A.L.; Reed, D.B.; McCool, B.; Dawson, J.A. mHealth improved fruit and vegetable accessibility and intake in young children. J. Nutr. Educ. Behav. 2019, 51, 556-566. [CrossRef]

17. Spring, B.; Pellegrini, C.; McFadden, H.G.; Pfammatter, A.F.; Stump, T.K.; Siddique, J.; King, A.C.; Hedeker, D. Multicomponent mHealth intervention for large, sustained change in multiple diet and activity risk behaviors: The make better choices 2 randomized controlled trial. J. Med. Internet Res. 2018, 20, e10528. [CrossRef]

18. Recio-Rodriguez, J.I.; Conde, C.A.; Calvo-Aponte, M.J.; Gonzalez-Viejo, N.; Fernandez-Alonso, C.; Mendizabal-Gallastegui, N.; Rodriguez-Martin, B.; Maderuelo-Fernandez, J.A.; Rodriguez-Sanchez, E.; Gomez-Marcos, M.A.; et al. The effectiveness of a smartphone application on modifying the intakes of macro and micronutrients in primary care: A randomized controlled trial. The EVIDENT II study. Nutrients 2018, 10, 1473. [CrossRef]

19. Nezami, B.T.; Ward, D.S.; Lytle, L.A.; Ennett, S.T.; Tate, D.F. A mHealth randomized controlled trial to reduce sugar-sweetened beverage intake in preschool-aged children. Pediatr. Obes. 2018, 13, 668-676. [CrossRef]

20. Liu, Z.; Wu, Y.; Niu, W.Y.; Feng, X.; Lin, Y.; Gao, A.; Zhang, F.; Fang, H.; Gao, P.; Li, H.J.; et al. A school-based, multi-faceted health promotion programme to prevent obesity among children: Protocol of a cluster-randomised controlled trial (the DECIDE-Children study). BMJ Open 2019, 9, e027902. [CrossRef] 
21. Smith, J.J.; Morgan, P.J.; Plotnikoff, R.C.; Dally, K.A.; Salmon, J.; Okely, A.D.; Finn, T.L.; Lubans, D.R. Smart-phone obesity prevention trial for adolescent boys in low-income communities: The ATLAS RCT. Pediatrics 2014, 134, e723-e731. [CrossRef] [PubMed]

22. Ainscough, K.M.; O’Brien, E.C.; Lindsay, K.L.; Kennelly, M.A.; O'Sullivan, E.J.; O’Brien, O.A.; McCarthy, M.; De Vito, G.; McAuliffe, F.M. Nutrition, behavior change and physical activity outcomes from the PEARS RCT-An mHealth-supported, lifestyle intervention among pregnant women with overweight and obesity. Front. Endocrinol. 2020, 10, 938. [CrossRef] [PubMed]

23. Kim, E.K.; Kwak, S.H.; Jung, H.S.; Koo, B.K.; Moon, M.K.; Lim, S.; Jang, H.C.; Park, K.S.; Cho, Y.M. The effect of a smartphonebased, patient-centered diabetes care system in patients with type 2 diabetes: A randomized, controlled trial for 24 weeks. Diabetes Care 2019, 42, 3-9. [CrossRef] [PubMed]

24. Dobson, R.; Whittaker, R.; Jiang, Y.; Maddison, R.; Shepherd, M.; McNamara, C.; Cutfield, R.; Khanolkar, M.; Murphy, R. Effectiveness of text message based, diabetes self management support programme (SMS4BG): Two arm, parallel randomised controlled trial. BMJ 2018, 361, 1959. [CrossRef] [PubMed]

25. Eyles, H.; McLean, R.; Neal, B.; Jiang, Y.; Doughty, R.N.; McLean, R.; Ni Mhurchu, C. A salt-reduction smartphone app supports lower-salt food purchases for people with cardiovascular disease: Findings from the SaltSwitch randomised controlled trial. Eur. J. Prev. Cardiol. 2017, 24, 1435-1444. [CrossRef]

26. Stevens, D.J.; McKenzie, K.; Cui, H.W.; Noble, J.G.; Turney, B.W. Smartphone apps for urolithiasis. Urolithiasis 2014, 43, 13-19. [CrossRef]

27. Costello, N.; Deighton, K.; Dyson, J.; Mckenna, J.; Jones, B. Snap-N-Send: A valid and reliable method for assessing the energy intake of elite adolescent athletes. Eur. J. Sport Sci. 2017, 17, 1044-1055. [CrossRef]

28. Simpson, A.; Gemming, L.; Baker, D.; Braakhuis, A. Do image-assisted mobile applications improve dietary habits, knowledge, and behaviours in elite athletes? A pilot study. Sports 2017, 5, 60. [CrossRef]

29. Belanger, M.J.; Hill, M.A.; Angelidi, A.M.; Dalamaga, M.; Sowers, J.R.; Mantzoros, C.S. Covid-19 and disparities in nutrition and obesity. N. Engl. J. Med. 2020, 383, e69. [CrossRef]

30. Im, J.H.; Je, Y.S.; Baek, J.; Chung, M.H.; Kwon, H.Y.; Lee, J.S. Nutritional status of patients with COVID-19. Int. J. Infect. Dis. 2020, 100, 390-393. [CrossRef]

31. Barazzoni, R.; Bischoff, S.C.; Breda, J.; Wickramasinghe, K.; Krznaric, Z.; Nitzan, D.; Pirlich, M.; Singer, P. ESPEN expert statements and practical guidance for nutritional management of individuals with SARS-CoV-2 infection. Clin. Nutr. 2020, 39, 1631-1638. [CrossRef]

32. Elezi, B.; Abazaj, E.; Kasa, M.; Topi, S. Prevention of frailty in the elderly through physical activity and nutrition. J. Geriatr. Med. Gerontol. 2020, 24, 6. [CrossRef]

33. Dunn, C.G.; Kenney, E.; Fleischhacker, S.E.; Bleich, S.N. Feeding low-income children during the Covid-19 pandemic. N. Engl. J. Med. 2020, 382, e40. [CrossRef]

34. Meyer, J.; McDowell, C.; Lansing, J.; Brower, C.; Smith, L.; Tully, M.; Herring, M. Changes in physical activity and sedentary behavior in response to COVID-19 and their associations with mental health in 3052 US Adults. Int. J. Environ. Res. Public Health 2020, 17, 6469. [CrossRef] [PubMed]

35. Maffoni, S.I.; Kalmpourtzidou, A.; Cena, H. The potential role of nutrition in mitigating the psychological impact of COVID-19 in healthcare workers. NFS J. 2021, 22, 6-8. [CrossRef]

36. Swan, W.I.; Vivanti, A.; Hakel-Smith, N.A.; Hotson, B.; Orrevall, Y.; Trostler, N.; Howarter, K.B.; Papoutsakis, C. Nutrition care process and model update: Toward realizing people-centered care and outcomes management. J. Acad. Nutr. Diet. 2017, 117, 2003-2014. [CrossRef] [PubMed]

37. Pellegrini, C.A.; Conroy, D.E.; Phillips, S.M.; Pfammatter, A.F.; McFadden, H.G.; Spring, B. Daily and seasonal influences on dietary self-monitoring using a smartphone application. J. Nutr. Educ. Behav. 2018, 50, 56-61.e1. [CrossRef] [PubMed]

38. Chin, S.O.; Keum, C.; Woo, J.; Park, J.; Choi, H.J.; Woo, J.T.; Rhee, S.Y. Successful weight reduction and maintenance by using a smartphone application in those with overweight and obesity. Sci. Rep. 2016, 6, 34563. [CrossRef] [PubMed]

39. Domhardt, M.; Tiefengrabner, M.; Dinic, R.; Fotschl, U.; Oostingh, G.J.; Stutz, T.; Stechemesser, L.; Weitgasser, R.; Ginzinger, S.W. Training of carbohydrate estimation for people with diabetes using mobile augmented reality. J. Diabetes Sci. Technol. 2015, 9 , 516-524. [CrossRef]

40. Lu, Y.; Stathopoulou, T.; Vasiloglou, M.F.; Pinault, L.F.; Kiley, C.; Spanakis, E.K.; Mougiakakou, S. goFOODTM: An artificial intelligence system for dietary assessment. Sensors 2020, 20, 4283. [CrossRef] [PubMed]

41. Vasiloglou, M.F.; Mougiakakou, S.; Aubry, E.; Bokelmann, A.; Fricker, R.; Gomes, F.; Guntermann, C.; Meyer, A.; Studerus, D.; Stanga, Z. A comparative study on carbohydrate estimation: GoCARB vs. Dietitians. Nutrients 2018, 10, 741. [CrossRef] [PubMed]

42. Rollo, M.E.; Ash, S.; Lyons-Wall, P.; Russell, A. Trial of a mobile phone method for recording dietary intake in adults with type 2 diabetes: Evaluation and implications for future applications. J. Telemed. Telecare 2011, 17, 318-323. [CrossRef] [PubMed]

43. Mezgec, S.; Seljak, B.K. Nutrinet: A deep learning food and drink image recognition system for dietary assessment. Nutrients 2017, 9, 657. [CrossRef] [PubMed] 
44. Krznarić, Ž.; Bender, D.V.; Laviano, A.; Cuerda, C.; Landi, F.; Monteiro, R.; Pirlich, M.; Barazzoni, R. A simple remote nutritional screening tool and practical guidance for nutritional care in primary practice during the COVID-19 pandemic. Clin. Nutr. 2020, 39, 1983-1987. [CrossRef]

45. Fernández-Quintela, A.; Milton-Laskibar, I.; Trepiana, J.; Gómez-Zorita, S.; Kajarabille, N.; Léniz, A.; González, M.; Portillo, M.P. Key aspects in nutritional management of COVID-19 patients. J. Clin. Med. 2020, 9, 2589. [CrossRef]

46. Alexander, J.; Tinkov, A.; Strand, T.A.; Alehagen, U.; Skalny, A.; Aaseth, J. Early nutritional interventions with zinc, selenium and vitamin D for raising anti-viral resistance against progressive COVID-19. Nutrients 2020, 12, 2358. [CrossRef]

47. Ipjian, M.L.; Johnston, C.S. Smartphone technology facilitates dietary change in healthy adults. Nutrition 2017, 33, 343-347. [CrossRef]

48. Sharp, D.B.; Allman-Farinelli, M. Feasibility and validity of mobile phones to assess dietary intake. Nutrition 2014, 30, 1257-1266. [CrossRef]

49. Gonzalez-Sanchez, J.; Recio-Rodriguez, J.I.; Fernandez-delRio, A.; Sanchez-Perez, A.; Magdalena-Belio, J.F.; Gomez-Marcos, M.A.; Garcia-Ortiz, L. Using a smartphone app in changing cardiovascular risk factors: A randomized controlled trial (EVIDENT II study). Int. J. Med. Inform. 2019, 125, 13-21. [CrossRef]

50. Whitelock, V.; Kersbergen, I.; Higgs, S.; Aveyard, P.; Halford, J.C.G.; Robinson, E. A smartphone based attentive eating intervention for energy intake and weight loss: Results from a randomised controlled trial. BMC Public Health 2019, 19, 6923. [CrossRef]

51. Kennelly, M.A.; Ainscough, K.; Lindsay, K.L.; O’Sullivan, E.; Gibney, E.R.; McCarthy, M.; Segurado, R.; DeVito, G.; Maguire, O.; Smith, T.; et al. Pregnancy exercise and nutrition with smartphone application support a randomized controlled trial. Proc. Obstet. Gynecol. 2018, 131, 818-826. [CrossRef]

52. Vega-López, S.; Ausman, L.M.; Griffith, J.L.; Lichtenstein, A.H. Interindividual variability and intra-individual reproducibility of glycemic index values for commercial white bread. Diabetes Care 2007, 30, 1412-1417. [CrossRef]

53. McMorrow, A.M.; Connaughton, R.M.; Magalhães, T.R.; McGillicuddy, F.C.; Hughes, M.F.; Cheishvili, D.D.; Morine, M.J.; Ennis, S.; Healy, M.L.; Roche, E.F.; et al. Personalized cardio-metabolic responses to an anti-inflammatory nutrition intervention in obese adolescents: A randomized controlled crossover trial. Mol. Nutr. Food Res. 2018, 62, 1008. [CrossRef]

54. Seto, E.; Hua, J.; Wu, L.; Bestick, A.; Shia, V.; Eom, S.; Han, J.; Wang, M.; Li, Y. The Kunming CalFit study: Modeling dietary behavioral patterns using smartphone data. Annu. Int. Conf. IEEE Eng. Med. Biol. Soc. 2014. [CrossRef]

55. Seto, E.; Hua, J.; Wu, L.; Shia, V.; Eom, S.; Wang, M.; Li, Y. Models of individual dietary behavior based on smartphone data: The influence of routine, physical activity, emotion, and food environment. PLoS ONE 2016, 11, e0153085. [CrossRef]

56. Goldstein, S.P.; Zhang, F.; Thomas, J.G.; Butryn, M.L.; Herbert, J.D.; Forman, E.M. Application of machine learning to predict dietary lapses during weight loss. J. Diabetes Sci. Technol. 2018, 12, 1045-1052. [CrossRef]

57. Hjorth, M.F.; Roager, H.M.; Larsen, T.M.; Poulsen, S.K.; Licht, T.R.; Bahl, M.I.; Zohar, Y.; Astrup, A. Pre-treatment microbial Prevotella-to-Bacteroides ratio, determines body fat loss success during a 6-month randomized controlled diet intervention. Int. J. Obes. 2018, 42, 580-583. [CrossRef]

58. Kovatcheva-Datchary, P.; Nilsson, A.; Akrami, R.; Lee, Y.S.; De Vadder, F.; Arora, T.; Hallen, A.; Martens, E.; Björck, I.; Bäckhed, F. Dietary fiber-induced improvement in glucose metabolism is associated with increased abundance of Prevotella. Cell Metab. 2015, 22, 971-982. [CrossRef] [PubMed]

59. Zeevi, D.; Korem, T.; Zmora, N.; Israeli, D.; Rothschild, D.; Weinberger, A.; Ben-Yacov, O.; Lador, D.; Avnit-Sagi, T.; Lotan-Pompan, M.; et al. Personalized nutrition by prediction of glycemic responses. Cell 2015, 163, 1079-1095. [CrossRef]

60. Albert, L.; Capel, I.; García-Sáez, G.; Martín-Redondo, P.; Hernando, M.E.; Rigla, M. Managing gestational diabetes mellitus using a smartphone application with artificial intelligence (SineDie) during the COVID-19 pandemic: Much more than just telemedicine. Diabetes Res. Clin. Pract. 2020, 169, 108396. [CrossRef] [PubMed]

61. Dávila, L.A.; Bermúdez, V.; Aparicio, D.; Céspedes, V.; Escobar, M.C.; Durán-Agüero, S.; Cisternas, S.; Costa, J.D.A.; Rojas-Gómez, D.; Reyna, N.; et al. Effect of oral nutritional supplements with sucromalt and isomaltulose versus standard formula on glycaemic index, entero-insular axis peptides and subjective appetite in patients with type 2 diabetes: A randomised cross-over study. Nutrients 2019, 11, 1477. [CrossRef]

62. Meng, H.; Matthan, N.R.; Ausman, L.M.; Lichtenstein, A.H. Effect of prior meal macronutrient composition on postprandial glycemic responses and glycemic index and glycemic load value determinations. Am. J. Clin. Nutr. 2017, 106, 1246-1256. [CrossRef] [PubMed]

63. McHill, A.W.; Czeisler, C.A.; Phillips, A.J.K.; Keating, L.; Barger, L.K.; Garaulet, M.; Scheer, F.A.J.L.; Klerman, E.B. Caloric and macronutrient intake differ with circadian phase and between lean and overweight young adults. Nutrients 2019, 11, 587. [CrossRef] [PubMed]

64. Gill, S.; Panda, S. A smartphone app reveals erratic diurnal eating patterns in humans that can be modulated for health benefits. Cell Metab. 2015, 22, 789-798. [CrossRef] [PubMed]

65. Lu, Z.; O'Dell, D.; Srinivasan, B.; Rey, E.; Wang, R.; Vemulapati, S.; Mehta, S.; Erickson, D.; Sommer, A. Rapid diagnostic testing platform for iron and Vitamin A deficiency. Proc. Natl. Acad. Sci. USA 2017, 114, 13513-13518. [CrossRef] [PubMed]

66. Lee, S.; O'Dell, D.; Hohenstein, J.; Colt, S.; Mehta, S.; Erickson, D. NutriPhone: A mobile platform for low-cost point-of-care quantification of Vitamin $B_{12}$ concentrations. Sci. Rep. 2016, 6, 28237. [CrossRef] [PubMed] 
67. Howe, K.B.; Suharlim, C.; Ueda, P.; Howe, D.; Kawachi, I.; Rimm, E.B. Gotta catch'em all! Pokémon GO and physical activity among young adults: Difference in differences study. BMJ 2016, 355, i6270. [CrossRef]

68. Puigdomenech, E.; Martin, A.; Lang, A.; Adorni, F.; Gomez, S.F.; McKinstry, B.; Prinelli, F.; Condon, L.; Rashid, R.; Caon, M.; et al. Promoting healthy teenage behaviour across three European countries through the use of a novel smartphone technology platform, PEGASO fit for future: Study protocol of a quasi-experimental, controlled, multi-Centre trial. BMC Med. Inform. Decis. Mak. 2019, 19, 278. [CrossRef] 